\title{
PROCESOS DE SIMILITUD Y CONTINUIDAD SEMANTICA EN "SOLA LA VOZ" DE HUGO LINDO
}

\author{
Bach. Leda Díaz
}

Los poemas de este libro, presentan varias unidades semánticas de interés para el análisis; no obstante en vista de que son muchos los poemas, se tomarán solo los diez primeros para comprobar de acuerdo con los planteamientos metodológicos señalados por R. Jakobson- la presencia de dos procesos: "El de similitud semántica y el de contigüidad semántica”.

Román Jakobson considera la existencia de dos líneas semánticas diferentes y la posibilidad de que en la poesía, por diferentes razones se elija entre alguna de ellas o bien se mezclen.

Estas líneas semánticas son:

a Un tema conduce a otro, sea por similitud,

b sea por contigüidad; ambas pueden ser posicionales o semánticas; en el primer caso domina lo meramente sintáctico; en el segundo hay implicaciones de significado.

El ejemplo que ofrece R. Jakobson aclara que dado un estímulo como la palabra "choza", una respuesta puede ser "ardió", otra "es una pobre casita".

Las dos reacciones se consideran predicativas, pero la primera crea un contexto puramente narrativo, mientras que en la segunda existe una doble conexión con el sujeto choza: por un lado lo que él llama contigüidad posicional (a saber, sintáctica), y por otra, una similitud semántica.

El mismo estímulo produjo las reacciones sus- titutivas siguientes: la tautología choza; los sinónimos cabaña y chozuel-a; el antónimo palacio y las metáforas antro y madriguera.

La capacidad que tienen dos palabras para reemplazarse la una por la otra es un ejemplo de similitud (o contraste semántico). Las respuestas al mismo estímulo tales como rastrojo, paja o pobreza, combinan y contrastan la similitud posicional con la contigüidad semántica.

En la obra de Hugo Lindo hay unidad semántica mediante el proceso de contigüidad y simititud. Para R. Jakobson en el primero hay preponderancia de la significación y una frase (o verso) aparecerá tras otra que le es anterior, puesta allí por el sujeto parlante (yo lírico), porque el desarrollo conceptual así lo exige.

En el segundo caso dos frases estarán vinculadas por una relación de similitud cuando el significante que sitúa en el mundo sensible del contenido semántico de la segunda, no es la prolongación o el desarrollo del significante correspondiente a la primera, sino que se le superpone en un auténtico proceso de profundización ${ }^{2}$.

Los cinco primeros poemas del libro, ofrecen varias unidades vinculadas por similitud semántica; cada una de ellas sustituye a la que le antecede para profundizar en el nivel de significación. El siguiente cuadro permite obtener mejor comprensión: en él, aparecen solo los términos claves que se sustituyen en cada unidad y no todo el verso. 


\begin{tabular}{|c|c|c|c|c|c|}
\hline & P.I & P.II & P.III & P.IV & P.V \\
\hline Se sustituyen: & VO $\rightarrow$ & VERSO $\rightarrow$ & I.U $\%$ AMOR, PALABRA $\rightarrow$ HOMBRF $\rightarrow$ & SER ANGUSTIADO $\rightarrow$ & YO TU \\
\hline
\end{tabular}

En el poema I (P.I) el yo lírico toma la voz como elemento base; todos los otros versos giran en torno a éste.

\section{"Quita de mi las voces para que sea solo la voz sin ruidos ${ }^{3}$}

En el P.II se observa la vinculación semántica con P.I. porque el yo lírico sustituye la voz por el verso y es este último el centro de todo lo que se enuncia.

\section{"Ahora voy descarnando el verso zrrancándole las palabras hasta el hueso" 4}

En el P.III son tres elementos los que sustituyen a verso y dentro del mismo poema hay un cuarto elemento que sirve de enlace con P.IV.

\section{"Yo hablo" ahora} de la Luz,del Amor, de la Palabra que es como hablar del Hombre" 5.

Entre este último verso del P.III y el primero de P.IV se establece un vínculo por similitud semántica.

\section{"Este ser angustiado que venia tropezando en la historia $y$ hallaba en la batalla o en el lecho la razón de su sangre" 6}

Se observa que lo acontecido en la unidad
P.IV es un "enriquecimiento" de lo enunciado en P.III, se crea de este modo un nuevo nivel de significado. El primer verso del P.IV es una metáfora del verso último del P.III(por efecto reflexivo de la metáfora, el verso último del P.III lo es del primero del P.IV); se ha sustituido el significante inicial Hombre por el nuevo Este ser angustiado.

El proceso continúa en P.V donde Este ser angustiado es sutituido por un yo-tú que configura otra unidad semántica, cuya aparición obedece a la necesidad de incorporar nuevas correspondencias de significación.
"Hablo de ti
De mi.
..
Del primer estertor.
De la manzana
y del llanto inicial de nuestros hijos."

En el P.I, II y III es evidente una unidad significativa en la que el yo lírico ha partido del Verbo para llegar luego en P.IV y V al Hombre.

Ha habido una actitud de ascenso en cuanto al nivel de significado. A partir de este momento en que se alcanza al Hombre en concreto, señalado como un yo algunas veces o como un yo-tu, otras, la mostración significativa apunta a las "vivencias" que padece, es Hombre.

Los otros cinco poemas aparecen enlazados por contigüidad semántica, ya que el desarrollo conceptual presente, así lo exige.

El cuadro esta vez, es el siguiente:

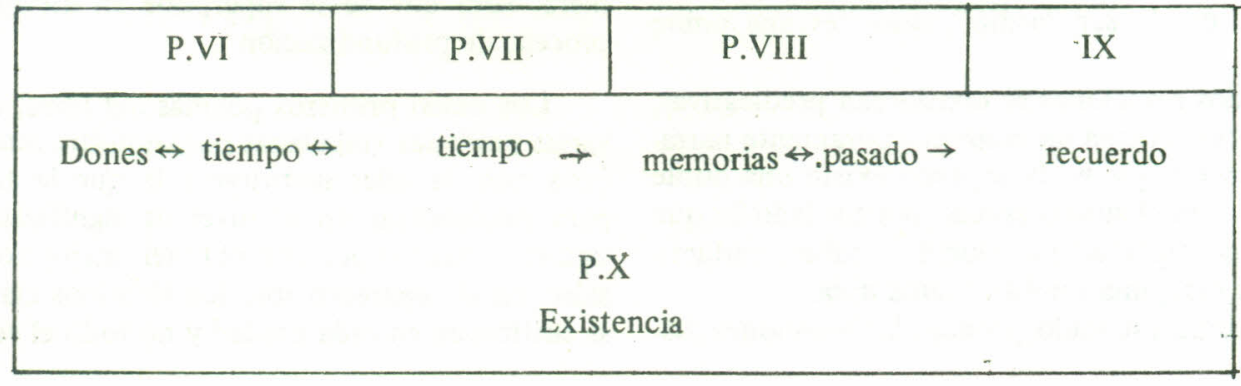


En P.VI el yo lírico habla de los dones presentes en la unidad yo-tú e implica al tiempo en estas vivencias.

"El don,los dones infinitos, tuyos.

Mios también. . ."

......

Porque el tiempo empezó cuando tus ojos o comenzó tal vez cuando mis manos."

El tiempo tiene su origen en el origen del yo o del tú; en este sentido hay correspondencia significativa con el P.V. en cuyos versos se aludía a un principio de vida (primer estertor etc.)

En el P.VIII, el tiempo ocupa todo el poema; señala, además, lo que éste representa para el yo y el tú. Por contigüidad semántica este poema, también se une al siguiente, donde el tiempo se convierte en el elemento memoria y consecuentemente viene a ser pasado (ayer celeste...)

"Memoria, vaso de nostalgias ayer celeste, irrepetible un recoger en la penumbra solo retazos del que fuiste",
En el P.IX la memoria se hace recuerdo puro

$$
\begin{aligned}
& \text { ". . que recuerdos } \\
& \text { por el silencio suave se deslizan"1 } 0
\end{aligned}
$$

E1 P.X cierra esta unidad semántica con el retorno del pasado al presente o sea, a lo que el yo lírico enuncia como la existencia misma; ahora todo vuelve a ser nuevo, hay' un comenzar de las cosas en el tú y los poemas siguientes llevan esa significación del retoño, de nuevo dia, de inicio etc.

"Pronuncio la existencia
como quien dice el fruto
En ti comienzan las palabras
a buscar rumbo nuevo
y los aromas a encontrarlo" 11

Las palabras, las vivencias, el cosmos del yo lírico va a ser nuevo y se instala en el presente para realizar sus cosas. He allí Solo la voz, convertida en síntesis del mundo, en donde, como en un rito, se reedita el ser de las cosas; he allí, pues, el valor proteico de la palabra, capaz de albergar las vicisitudes todas de la existencia.
1- LINDO, Hugo. Solo la voz. Ministerio de Educación. Dirección General de Cultura. Dirección de Publicaciones. E1 Salvador, 1968.

2- JAKOBSON, Roman y Juan A. Magariños. Semiologia, afasia y discurso psicótico. Planteos estructurales. Edición a cargo del Instîtuto y Laboratorio de Análisis Estructurales. Buenos Aires, Argentina, 1973.

3- Hugo Lindo. Opus cit. P.9
Ibid. P.11

Ibid. P.13

Ibid. P.15

7- Ibid. p.17

8- Ibid. p.19

9- Ibid. p.23

10- Ibid. p.19

11- Ibid. p.23

12- Ibid. p.26

13- Ibid. p. 28 
